\title{
A feedback learning and mental models perspective on strategic decision making
}

\author{
Carlos Capelo $\cdot$ João Ferreira Dias
}

(C) Association for Educational Communications and Technology 2009

\begin{abstract}
This study aims to be a contribution to a theoretical model that explains the effectiveness of the learning and decision-making processes by means of a feedback and mental models perspective. With appropriate mental models, managers should be able to improve their capacity to deal with dynamically complex contexts, in order to achieve long-term success. We present a set of hypotheses about the influence of feedback information and systems thinking facilitation on mental models and management performance. We explore, under controlled conditions, the role of mental models in terms of structure and behaviour. A test based on a simulation experiment with a system dynamics model was performed. Three out of the four hypotheses were confirmed. Causal diagramming positively influences mental model structure similarity, mental model structure similarity positively influences mental model behaviour similarity, and mental model behaviour similarity positively influences the quality of the decision.
\end{abstract}

Keywords Mental model · Double-loop learning · Systems thinking · Simulation experiment

The perspective of strategic decision making as a cognitive and learning process has gained importance in recent years with empirical findings and theory now widely recognized by both academics and practitioners. In particular, an alternative approach to the cognitive analysis of strategic decision processes has arisen that explores the content of managers' mental representations of strategic problems. This approach involves mental models, used by managers to interpret the world around them. This stream of work is predicated on the assumption that organizational strategy is strongly influenced by managers' mental models,

C. Capelo $(\bowtie)$

Universidade Lusófona, Campo Grande, 376, 1749-024 Lisbon, Portugal

e-mail: carlos.capelo@galpenergia.com

J. F. Dias

EBAP-Fundação Getúlio Vargas, Rio de Janeiro, Brazil

e-mail: joao.ferreira.dias@gmail.com 
which are simplified and incomplete representations of reality. Managers forecast the future through the lens provided by mental models built up through past experience. Managers access and develop analytical frameworks and information systems to help them determine their organization's strategy. However, what managers ultimately decide is influenced by the mental models they carry around inside their heads. Mental models (Craik 1943; Johnson-Laird 1983; Gentner and Stevens 1983) have been commonly used in systems thinking and modeling literature (Forrester 1961; Huff and Jenkins 2002; Morecroft et al. 2002; Pidd 2004; Senge 1990; Sterman 2000). From a systems perspective, a mental model is a conceptual representation of the structure of an external system used by people to describe, explain and predict a system's behavior. Managers deal continuously with these mental models of the business system. These mental models are not identical with external realities; they are not necessarily correct; they are models of the real system that is being represented. Managers refine their mental models as they interact with the business system that they manage. Experimental research has suggested that decision makers perform better if the structure of their mental model is more similar to the structure of the external system it represents (Davis and Yi 2004; Mathieu et al. 2000, 2005; Rowe and Cooke 1995; Stout et al. 1996; Wyman and Randel 1998). In particular, experiments using interactive computer-based simulations (Gary and Wood 2007; Ritchie-Dunham 2002) have shown that the accuracy of a person's mental model is a good predictor of their performance. Thus, it is reasonable to assume that, by enhancing their mental models, managers should be able to improve their capacity to deal with dynamically complex relationships. This in turn would improve their ability to manage the business system in order to achieve long-term success.

This research is grounded on the dynamic model of decision-making process as presented in Fig. 1. Managers make decisions and learn in the context of feedback loops. In single-loop learning, managers compare information about the state of a real system to preestablished goals, perceive deviations between desired and actual states, and make the decisions they believe will move the system towards the desired state (L1 in Fig. 1). Single-loop learning does not change the managers' mental models. In double-loop learning (L1/L2/L3 in Fig. 1), information about the business system is not only used to

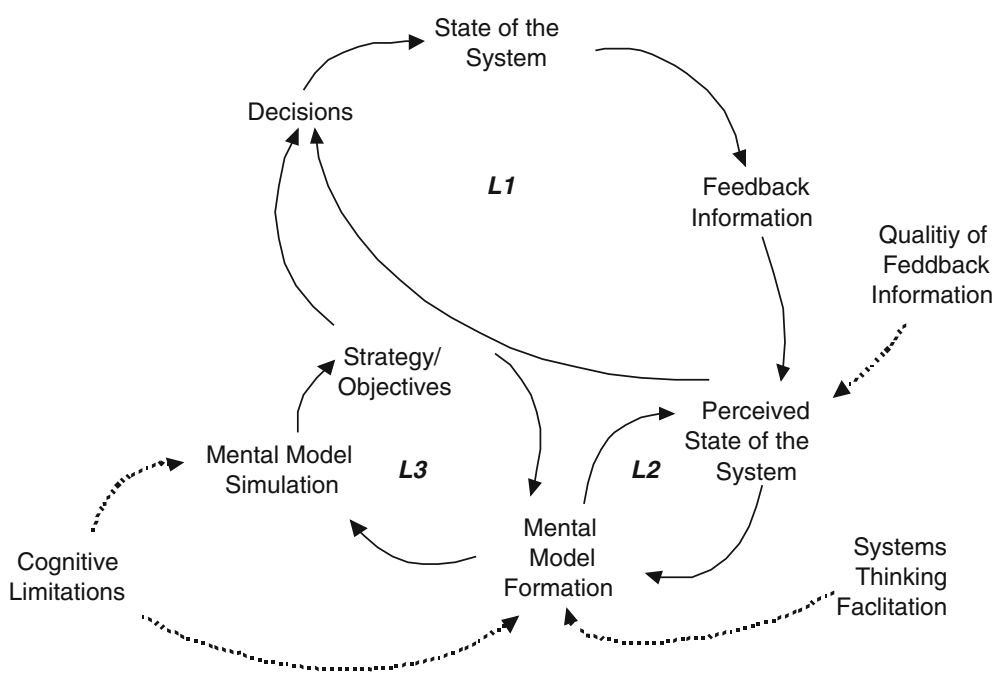

Fig. 1 Dynamic model of a decision-making process. Notes: $L 1$ heuristic decision making loop, $L 2$ mental model formation/perception loop, $L 3$ strategy/objectives-changing loop 
make decisions within the context of existing frames, but also feeds back to modify the managers' mental models (Argyris 1976). As their mental models change, managers use them to anticipate and evaluate the consequences of alterative strategic choices, resulting in new strategies and policies.

As represented in Fig. 1, cognitive limitations and quality of feedback information are key factors that impact the effectiveness of double-loop learning because they have the potential to limit managers' perception and understanding of the actual business system (Richardson et al. 1994; Sterman 2000). Due to cognitive limitations, the mental models that managers use for decision making are necessarily imperfect, with the result that a flawless assessment of the dynamic behavior of the business system is nearly impossible. Strategic learning processes are also strongly influenced by the quality of information fed back about the state of the business system. Managers use that information to interact with the business system. In the event of imperfect feedback information, managers have an incorrect perception of the impact of their decisions, and so they are unable to build their mental models accurately. Thus, appropriate tools must be designed and implemented in order to overcome or minimize these barriers to strategic learning.

A significant number of systemic approaches and techniques have been developed in order to support and accelerate the managers' learning process. These usually involve interpretative modelling and simulation techniques to understand the dynamic behaviour of a system (Checkland and Scholes 1990; Eden and Ackermann 1998; Senge 1990; Sterman 2000). Most of these approaches include causal diagrams, cognitive maps or strategy maps, used as systems thinking tools that support managers to model and review organizational strategy. Causal diagrams facilitate managers to translate, test and communicate their understanding of the business system. In other words, causal diagramming triggers a process by which managers can make explicit and improved mental models of the decision context. Then they adapt the organization strategy and define new objectives as they reflect about the consequences of alternative choices by simulating their mental models to infer the future behaviour of the business system.

A considerable amount of research and theory have been developed concerning the design and evaluation of feedback learning strategies in the area of education (Narciss 2008). According to this large body of research, the effectiveness of feedback strategies depends immensely on how the performance information is provided to learners and how they process that information both externally and internally. Differentiating external feedback (presented by an external source) from internal feedback (provided by internal sources of information) and considering the interaction between internal and external feedback are crucial when investigating the effects of learning strategies.

The following sections describe a simulation-based research aimed to explore the role of mental models in the strategic decision making process, under different conditions in terms of systems thinking facilitation and quality of feedback information. The analysis of subjects' mental models considers two properties: its structure (the external representation of subjects' mental models in terms of a conceptual causal chain incorporating some critical variables of the business system) and its behavior (the mentally simulated consequences of the selected strategy).

\section{Research model}

This research focuses on how quality of feedback information and systems thinking facilitation foster mental models formation and simulation, leading to the improvement of 


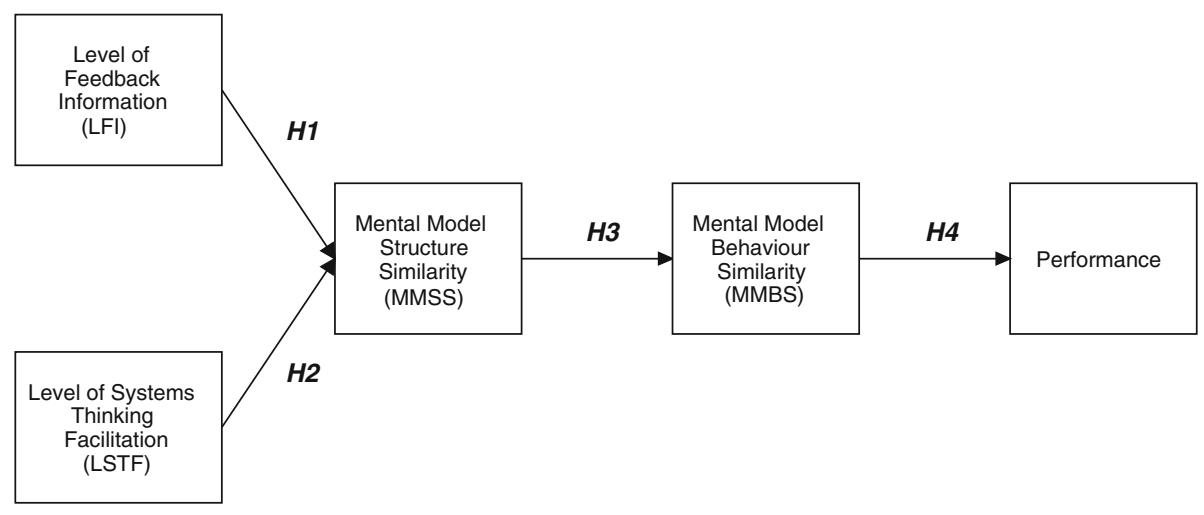

Fig. 2 Model of hypotheses

the strategy formulation and implementation process. The model of hypotheses, based on the following variables and expected relations, are pictured in Fig. 2.

Level of Feedback Information (LFI) - this variable represents the quality level of feedback information. LFI indicates to what extent feedback information captures comprehensively the essential of the business system behaviour.

Level of Systems Thinking Facilitation (LSTF) - this variable represents the intensity of systems thinking tools utilization to support the process of strategy review and implementation.

Mental Model Structure Similarity (MMSS) — this variable represents the participants' understanding of the structure of the simulated business system, and measures the similarity between the structure of the external representation of the managers' mental models and the structure of the business system.

Mental Model Behaviour Similarity (MMBS) — this variable represents the participants' understanding of the behaviour of the simulated business system. MMBS measures the similarity between the manager's expectation on system behaviour (simulation of manager's mental models) and the actual behaviour of the business system.

Performance-the performance of this management task is measured in terms of the financial value created by the firm.

A higher Level of Feedback Information provides more relevant, essential and comprehensive information about business system behaviour that drives future performance. By using a higher Level of Feedback Information, managers access more accurate information to interact with the business system, and they acquire a sharper perception of the impact of their decisions. This relation improves the ability to build more accurate mental models, leading to higher Mental Model Structure Similarity. In other words, the present work assumes that if managers use higher level of feedback information in the process of strategic review and implementation, they build more appropriate mental models.

Hypothesis 1 The Level of Feedback Information positively influences Mental Model Structure Similarity.

It is assumed that by using systems thinking tools, managers have more effective learning as they review the critical cause-and-effect relations through a process that makes explicit and improve their mental models of the business system. 
Hypothesis 2 The Level of Systems Thinking Facilitation positively influences Mental Model Structure Similarity.

This research assumes that managers assess the consequences of their decisions more accurately if the structure of their mental models is as similar as possible to the structure of the external system it represents.

Hypothesis 3 Mental Model Structure Similarity positively influences Mental Model Behaviour Similarity.

It is assumed that managers perform better if they evaluate the consequences of their decisions more accurately.

Hypothesis 4 Mental Model Behaviour positively influences Performance (financial value creation).

\section{Method}

In several areas of management research, computer simulators are well accepted and frequently used as instruments for investigating human cognition and decision making in complex business situations (Howie et al. 2000; Paich and Sterman 1993; Sengupta and Abdel-Hamid 1993; Sterman 1989). We considered a system dynamics model to be an appropriate research tool for our problem. The hypotheses defined in this research and presented in the previous section were tested with a simulation-based experiment in which subjects interacted with a system dynamics micro world that provided information through different interfaces. This section presents an overview of the chosen simulator, describes the subjects and the experiment conditions, and overviews the research model variables.

\section{Simulator overview}

The business simulator was built by incorporating the same system dynamics model that had been used in previous research (Ritchie-Dunham 2002). The participants run a realistic simulator of a wireless telecommunications firm by making critical decisions every 6 months for a simulation period of 7 years. The simulator provides two alternative interfaces. One represents a financial scorecard interface which features EBIT (earnings before interest and taxes) and other measures that are directly related to its calculation. The other interface represents a balanced scorecard that includes a set of leading and lagging measures that are graphically separated into four sections related to the four perspectives associated with the BSC (Balanced Scorecard) approach (Financial, Customers, Internal Processes, Learning and Growth) (Kaplan and Norton 2001). Each simulator interface includes three screens: the first screen allows participants to enter their decisions and provides data for that time period; the second screen presents the historical behaviour over time for each of the variables in the first screen; the third screen provides a description of each of the variables in use.

The participant objective was to develop critical and interrelated resources at appropriate rates and levels in order to gain and retain customers, operate efficiently, and maximize value creation. To succeed in this simulation task, participants had to identify and understand the cause-and-effect relationships among critical variables in order to anticipate and evaluate the consequences of alternative decisions. 
Subjects, apparatus, procedure, and facilitation

This research was conducted at ISCTE (a business graduate school in Lisbon) and at Galp Energia, a Portuguese oil company, involving 73 subjects. The simulation task was performed individually (participants could not interact), anonymously and without financial rewards or incentives. All the participants were familiar with basic BSC concepts and with the financial measures used to calculate and define task performance. The decisions made on the simulation and its results were automatically stored in a protected spreadsheet on the participant's computer. Each participant took about 120 min to perform the task.

In the simulation experiment, the participants were involved in the dynamical decisionmaking processes presented in Fig. 3. They analyzed business status using the simulator interface, used this information to review the strategy and objectives and decision making, and then repeated the process. There were three different stages. In stage A the participants ran the firm by using the financial scorecard interface; in stage B the firm was operated using the balanced scorecard interface; and in stage $\mathrm{C}$ the firm was run by using the balanced scorecard and a causal diagram representing the strategic map tool of the BSC approach (Kaplan and Norton 2001).

As shown in Figs. 3 and 4, stages A and B had the same procedure and involved one session. The procedure for stage $\mathrm{C}$ was different as subjects reviewed the causal diagram (strategy map) and participated in two sessions. The experimental procedures had the following common initial steps. Firstly, the participants were randomly assigned to one of three stages (A, B or C). Next, they answered some questions (age, simulation experience, and management experience), and they read the introduction with the overall description and the objectives of the simulation and the business case study.

For stages $\mathrm{A}$ and $\mathrm{B}$, in the same session, the participants read the instructions for accessing, starting and running the simulator and they were given oral instructions with

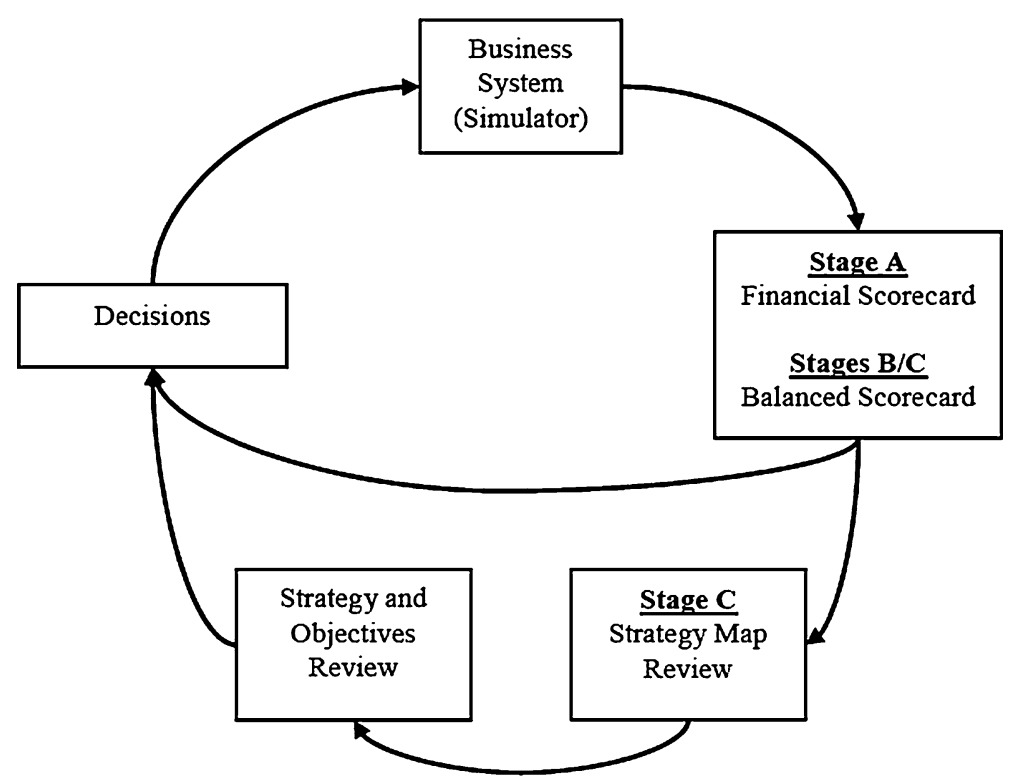

Fig. 3 Stages in a dynamic decision-making process 
Experimental procedure for Stages A and B - strategy map is not used

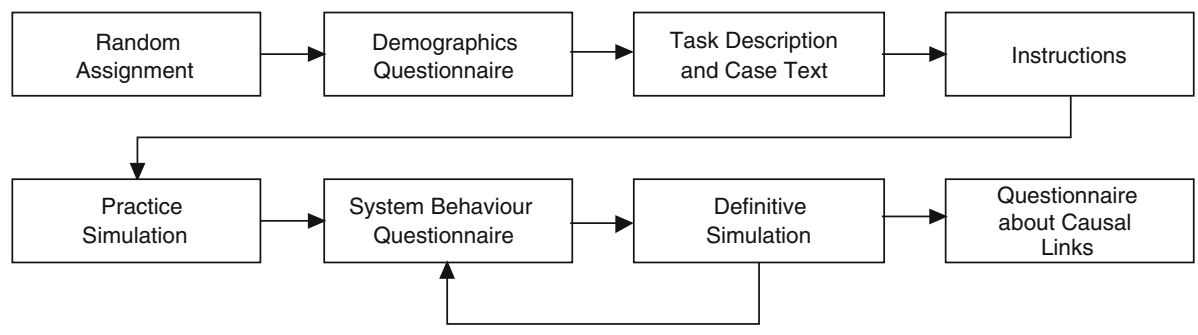

Experimental procedure for Stage $\mathrm{C}$ - with strategy map review

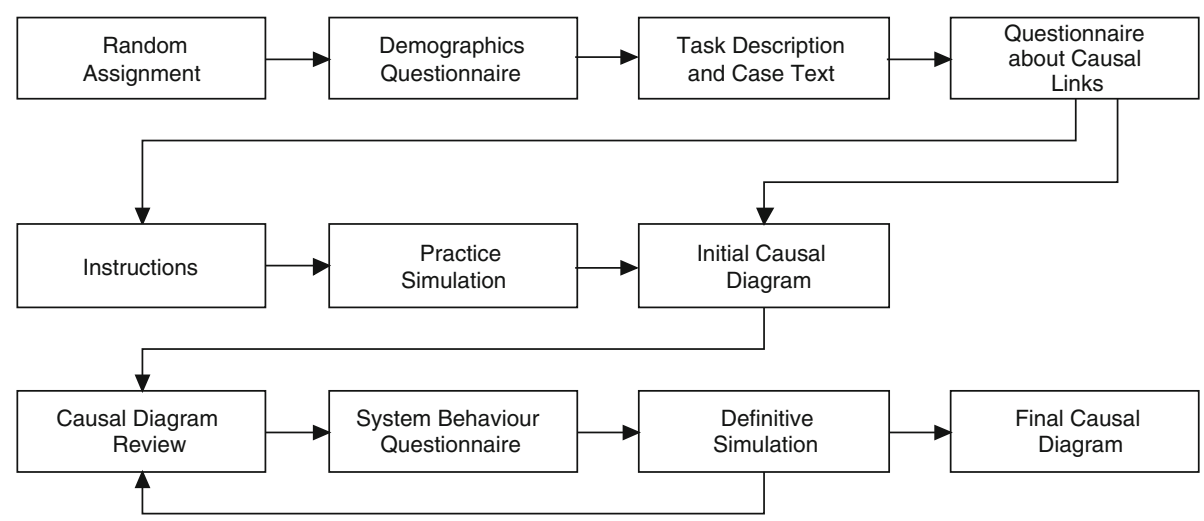

Fig. 4 Experimental procedures

examples to show the simulator operation. A first simulation was conducted to familiarize participants with the game interfaces and commands. The actual experiment involved a second simulation that included a questionnaire about the expected behaviour of some critical variables every 2 years of simulation time. After the simulation, the participants answered a questionnaire about their understanding of the linkages between certain critical concepts.

The first session of stage $\mathrm{C}$ called for participants to read the business case text, before performing the following steps. Firstly, the participants filled out the same questionnaire that was used on the final step of stages A and B about their ultimate understanding of the linkages between certain critical variables - this questionnaire captured their initial level of comprehension of the business system. The answers to that questionnaire were translated into a network diagram using the Pathfinder procedure (Rowe and Cooke 1995; Schvaneveldt 1990). The second session commenced with the analysis of an initial strategy map (causal diagram), drawn from the previous network diagram, that showed the linkages among critical concepts. Participants received instructions in how to read and interpret the initial causal diagram, and how to review it by cutting or inserting links between the indicators and defining the arrows that indicated the cause-and-effect relationships. Since the initial causal diagram only showed linkages among concepts, they were encouraged to draw arrows to define the cause-and-effect relationships among those variables (example in Fig. 5). Next, they read the instructions for accessing, starting and running the simulator. 


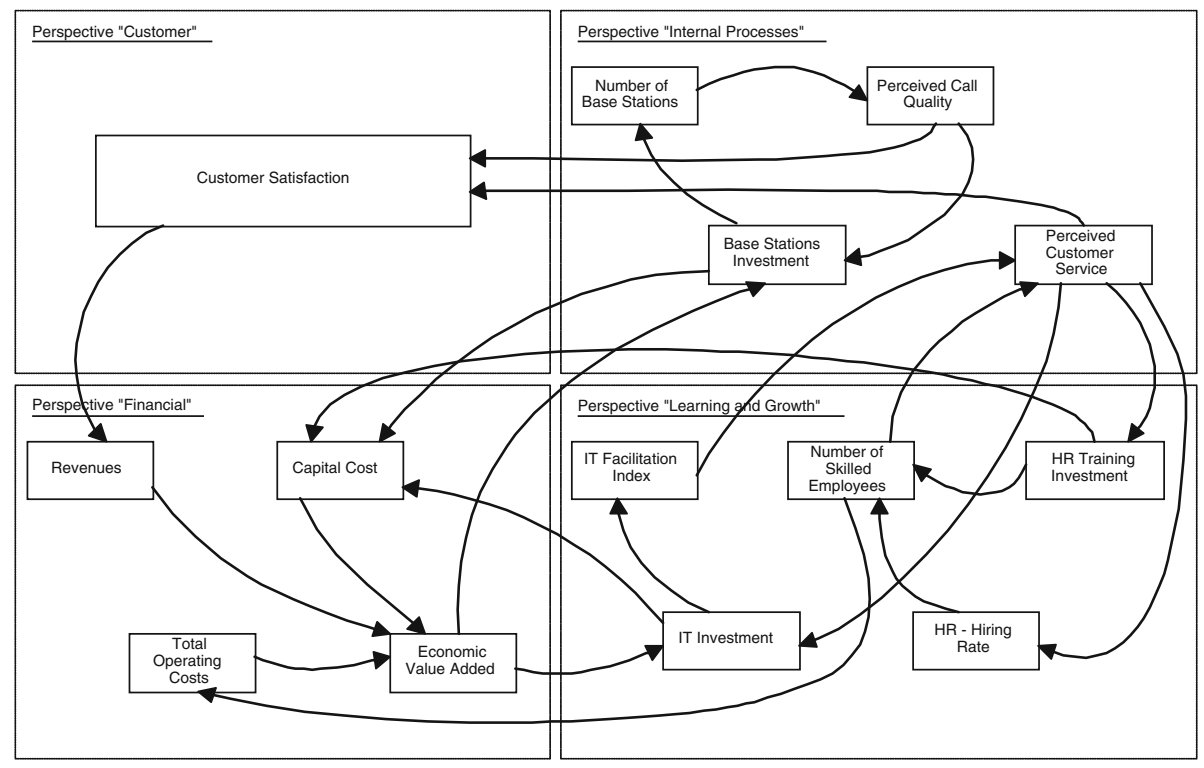

Fig. 5 Causal diagram (strategy map) with the representative network of the simulated business system

They ran a first simulation to familiarize themselves with the game interfaces and commands. Finally the participants performed the simulation that represented the actual experiment; as during stages $\mathrm{A}$ and $\mathrm{B}$, they also answered a questionnaire about strategy and objectives every 2 years of simulation time; however, this experimental group was also asked to review the causal diagram (strategy map) which had been provided in the experiment guide. They cut or inserted links so that the causal diagram accurately expressed their latest understanding of the simulated business system. The participants were also encouraged to use the strategy map to reflect on strategy, objectives, and decisions. Finally, they drafted a final strategy map-this map represented their ultimate understanding of the business system.

Research model variables

This section summarizes the use of the variables Level of Feedback Information, Level of Systems Thinking Facilitation, Mental Model Structure Similarity, Mental Model Behaviour Similarity, and Performance that were defined in the research model. In order to perform some exploratory analysis, the following variables were also defined and measured: Time (total time participants spent on the task); Age (participant age); Simulation Experience (previous experience with management simulators); Work Experience (previous work experience in management).

Level of Feedback Information (LFI) - the variable Level of Feedback Information features two degrees. In the low degree (low LFI), the subjects ran the firm using the financial scorecard interface (stage A); in the high degree (high LFI) the balanced scorecard interface is used (stages B and C). By using a balance scorecard interface, participants access more critical and relevant information to interact with the business system, acquiring a sharper perception of the impact of their decisions. 
Level of Systems Thinking Facilitation (LSTF) - the variable Level of Systems Thinking Facilitation also features two degrees. In the low degree (low LSTF), the participants ignore the causal diagram (strategy map) while running the simulator (stages A and B); in the high degree (high LSTF), the causal diagram (strategy map) is used to define and review the strategy and objectives (stage $\mathrm{C}$ ). The causal diagram used in this experiment contains some critical simulator concepts spatially organized in four set of indicators related to the four perspectives of the balanced scorecard, representing the strategy map tool of the BSC approach. The causal diagram utilization is described in the previous section (under stage $\mathrm{C}$ procedures).

Mental Model Structure Similarity (MMSM) - the variable Mental Model Structure Similarity represents the participants' understanding of the structure of the simulated business system. As the structure of the simulated business system is known by the researchers in advance, it can be compared with the participants' mental model in order to evaluate how that elicited mental model matched the simulated reality. This variable measures the similarity between the structure of the external representation of the subjects' mental models and the representative structure of the simulator (Fig. 5) (Rowe and Cooke 1995).

In the lower level of Systems Thinking Facilitation (defined in connection with stages A and $\mathrm{B}$ in the previous section), the participants were asked to fill out a questionnaire detailing their final understanding of the simulated business system. This questionnaire used a nine-point scale, to evaluate the relatedness of 14 concepts in the simulation model (Rowe and Cooke 1995). The 14 concepts are relevant to understand the simulated business system. The 91 pairings needed to relate the 14 concepts $\left(n^{2} / 2-n / 2=14^{2} / 2-14 / 2=\right.$ 91) were presented in random order. The structure of the external representation of the participant's mental model could be elicited by this pair-wise relatedness ratings technique. These elicited pairings were transformed into a network diagram using a network scaling procedure pathfinder (Schvaneveldt 1990). In the higher Level of Systems Thinking Facilitation (defined in the previous section stage $\mathrm{C}$ under the discussion of stage $\mathrm{C}$ ) the participants produced a final causal diagram linking the same 14 concepts as were found in the simulation model. This final causal diagram represented the elicited structure of the external representation of the subjects' mental model. Mental Model Structure Similarity was measured in terms of the similarity between two networks - the external representation of the participants' mental model and the representative network of the simulator. This network similarity ranged from 0 (low similarity) to 1 (high similarity) and was determined by the number of links in common divided by the total number of links in both networks (Rowe and Cooke 1995; Schvaneveldt 1990).

Mental Model Behaviour Similarity (MMBS) — this variable represents the participants' understanding of the behaviour of the simulated business system. MMBS measures the similarity between the subject's expectation on system behaviour (simulation of manager's mental models) and the actual behaviour of the business system. This similarity ranges from 0 (low similarity) to 1 (high similarity) and is determined by the number of correct answers regarding to the behaviour of certain critical variables divided by the total number of questions.

Performance-task performance was measured by total financial value creation. This value was estimated by summing the discounted economic profit or economic value added (defined as Net Operating Profit Less Amortizations and Taxes - Weighted Average Cost of Capital $\times$ Total Capital Employed) of the firm over the seven simulated years (Copeland et al. 2000). 


\section{Results and discussion}

The 73 participants were grouped as follows: stage A-using financial scorecard interface without causal diagramming (low Level of Feedback Information, low Level of Systems Thinking Facilitation) - 24 participants; stage B-using balanced scorecard interface without causal diagramming (high LFI, low LSTF)—24 participants; stage C-using balanced scorecard interface and causal diagramming (high LFI, high LSTF) - 25 participants. Table 1 presents minimum, maximum and mean values, and standard deviations for the dependent variables of each stage group. Table 2 shows the results of statistical testing to identify differences in means between the stage groups.

The participants in group C-high Level of Feedback Information and high Level of Systems Thinking Facilitation-showed on average the best Mental Model Structure Similarity $($ mean $=0.443)$, the best Mental Model Behaviour Similarity $($ mean $=0.742$ ) and the best Performance (mean $=628$ ). As shown in Table 2, the mean values of Mental Model Structure Similarity, Mental Model Behaviour Similarity and Performance for group $\mathrm{C}$ were significantly different from the equivalent values for groups $\mathrm{A}$ and $\mathrm{B}$. On average, the participants of group B-high Level of Feedback Information-showed a better Mental Model Structure Similarity (mean $=0.295$ ) than participants of group A (mean $=0.250$ ) - low Level of Feedback Information. Table 2 shows that the difference is significant at $P<0.05$ (mean difference $=0.045, P=0.043$ ). Participants of group A and participants of group B showed similar mean values for Mental Model Behaviour Similarity (mean difference $=-0.035, P=0.594$ ) and Performance (mean difference $=18$, $P=0.925)$.

Table 1 Means and standard deviations for mental model structure similarity, mental model behaviour similarity and performance for each stage group

\begin{tabular}{|c|c|c|c|c|c|c|c|c|c|}
\hline \multirow[t]{2}{*}{ Stage } & \multicolumn{3}{|c|}{ Mental model structure similarity } & \multicolumn{3}{|c|}{ Mental model behaviour similarity } & \multicolumn{3}{|l|}{ Performance } \\
\hline & $\operatorname{Min} / \max$ & Mean & $\begin{array}{l}\text { Stand. } \\
\text { dev. }\end{array}$ & $\operatorname{Min} / \max$ & Mean & $\begin{array}{l}\text { Stand. } \\
\text { dev. }\end{array}$ & $\operatorname{Min} / \max$ & Mean & $\begin{array}{l}\text { Stand. } \\
\text { dev. }\end{array}$ \\
\hline A & $0.122 / 0.406$ & 0.250 & 0.080 & $0.20 / 0.850$ & 0.567 & 0.185 & $-715 / 854$ & 329 & 450 \\
\hline B & $0.093 / 0.429$ & 0.295 & 0.077 & $0.200 / 0.950$ & 0.602 & 0.224 & $-1148 / 1189$ & 310 & 687 \\
\hline $\mathrm{C}$ & $0.205 / 0.708$ & 0.443 & 0.126 & $0.550 / 0.900$ & 0.742 & 0.095 & $-432 / 1089$ & 628 & 409 \\
\hline
\end{tabular}

Table 2 Test of significance for difference in means between stage groups $(t$-test; df $=329)$

\begin{tabular}{|c|c|c|c|c|c|c|c|c|c|}
\hline \multirow[t]{2}{*}{ Pair } & \multicolumn{3}{|c|}{$\begin{array}{l}\text { Mental model structure } \\
\text { similarity }\end{array}$} & \multicolumn{3}{|c|}{$\begin{array}{l}\text { Mental model behaviour } \\
\text { similarity }\end{array}$} & \multicolumn{3}{|c|}{ Performance } \\
\hline & $\begin{array}{l}\text { Mean } \\
\text { difference }\end{array}$ & $\begin{array}{l}\text { Stand. } \\
\text { dev. }\end{array}$ & Significance & $\begin{array}{l}\text { Mean } \\
\text { difference }\end{array}$ & $\begin{array}{l}\text { Stand. } \\
\text { dev. }\end{array}$ & Significance & $\begin{array}{l}\text { Mean } \\
\text { difference }\end{array}$ & $\begin{array}{l}\text { Stand. } \\
\text { dev. }\end{array}$ & Significance \\
\hline $\mathrm{A}-\mathrm{B}$ & $-0.045^{*}$ & 0.102 & 0.043 & -0.035 & 0.321 & 0.594 & 18 & 939 & 0.925 \\
\hline $\mathrm{B}-\mathrm{C}$ & $-0.144 * *$ & 0.153 & 0.000 & $-0.177 * *$ & 0.204 & 0.000 & $-313^{*}$ & 632 & 0.023 \\
\hline $\mathrm{A}-\mathrm{C}$ & $-0.189 * *$ & 0.139 & 0.000 & $-0.142 *$ & 0.269 & 0.017 & $-295^{*}$ & 592 & 0.023 \\
\hline
\end{tabular}

$* P<0.05$

** $P<0.001$ 
The lowest values for the variables Mental Model Similarity and Performance were found in participants from group B-balanced scorecard interface (Table 1). This result may be explained by the overload caused by an excessive amount of information, much larger than the information volume that was processed by participants of group A with financial scorecard interface. This may have led participants to misinterpret the indicators structure and behaviour.

The results suggest that causal diagramming gave participants in group $\mathrm{C}$ a significant cognitive aid that accelerated their learning about the simulated business system. This simulation experiment did not involve a formal briefing session. However, after being informed about the global results, some participants of group $\mathrm{C}$ argued that by accessing and reviewing the initial causal diagram just after finishing the practice simulation, they tested their initial assumptions more effectively. Therefore, they may have benefited right from the start of the simulation that constituted the actual experiment with a better understanding of the simulator.

Table 3 shows the results of multivariate regression analysis of Mental Model Structure Similarity, Mental Model Structure Behaviour Similarity and Performance on the independent variables. The regressions were run on standardized values for all the variables so as to directly compare the relative effects of each independent variable on the dependent variable. As presented in Table 3, regression analysis for Mental Model Structure Similarity on the independent variables shows a highly significant positive effect for Level of Systems Thinking Facilitation $(\beta=0.575, P<0.001)$, a significant positive effect for Level of Feedback Information $(\beta=0.241, P=0.037)$ and no significant effects for other variables. Regression analysis of Mental Model Behaviour Similarity on the independent variables shows a significant positive effect for Mental Model Structure Similarity $(\beta=0.320, P<0.041)$, a significant negative effect for Age $(\beta=-0.318, P=0.037)$, a

Table 3 Regression results for all independent variables

\begin{tabular}{|c|c|c|c|c|c|c|}
\hline \multirow{3}{*}{$\begin{array}{l}\text { Independent } \\
\text { variables }\end{array}$} & \multicolumn{6}{|c|}{ Dependent variables } \\
\hline & \multicolumn{2}{|c|}{$\begin{array}{l}\text { Mental model structure } \\
\text { similarity }\end{array}$} & \multicolumn{2}{|c|}{$\begin{array}{l}\text { Mental model behaviour } \\
\text { similarity }\end{array}$} & \multicolumn{2}{|l|}{ Performance } \\
\hline & $\begin{array}{l}\text { Standardized } \\
\text { beta }\end{array}$ & $\begin{array}{l}\text { Significance } \\
\mathrm{p}\end{array}$ & $\begin{array}{l}\text { Standardized } \\
\text { beta }\end{array}$ & $\begin{array}{l}\text { Significance } \\
\mathrm{p}\end{array}$ & $\begin{array}{l}\text { Standardized } \\
\text { beta }\end{array}$ & $\begin{array}{l}\text { Significance } \\
\mathrm{p}\end{array}$ \\
\hline Time & -0.025 & 0.814 & 0.106 & 0.398 & -0.009 & 0.926 \\
\hline Age & 0.047 & 0.710 & $-0.318^{*}$ & 0.037 & -0.110 & 0.376 \\
\hline Work experience & 0.193 & 0.137 & $0.388 *$ & 0.015 & 0.044 & 0.737 \\
\hline $\begin{array}{l}\text { Simulation } \\
\text { experience }\end{array}$ & -0.156 & 0.159 & -0.002 & 0.990 & $0.212 *$ & 0.049 \\
\hline LFI & $0.241 *$ & 0.037 & 0.118 & 0.398 & -0.100 & 0.370 \\
\hline LSTF & $0.575 * * *$ & 0.000 & 0.069 & 0.657 & -0.164 & 0.191 \\
\hline MMSS & & & $0.320 *$ & 0.041 & $0.401 * *$ & 0.002 \\
\hline MMBS & & & & & $0.540 * * *$ & 0.000 \\
\hline Adjusted $\mathrm{R}^{2}$ & 0.432 & & 0.204 & & 0.494 & \\
\hline
\end{tabular}

\footnotetext{
$* P<0.05$

** $P<0.005$

*** $P<0.001$
} 


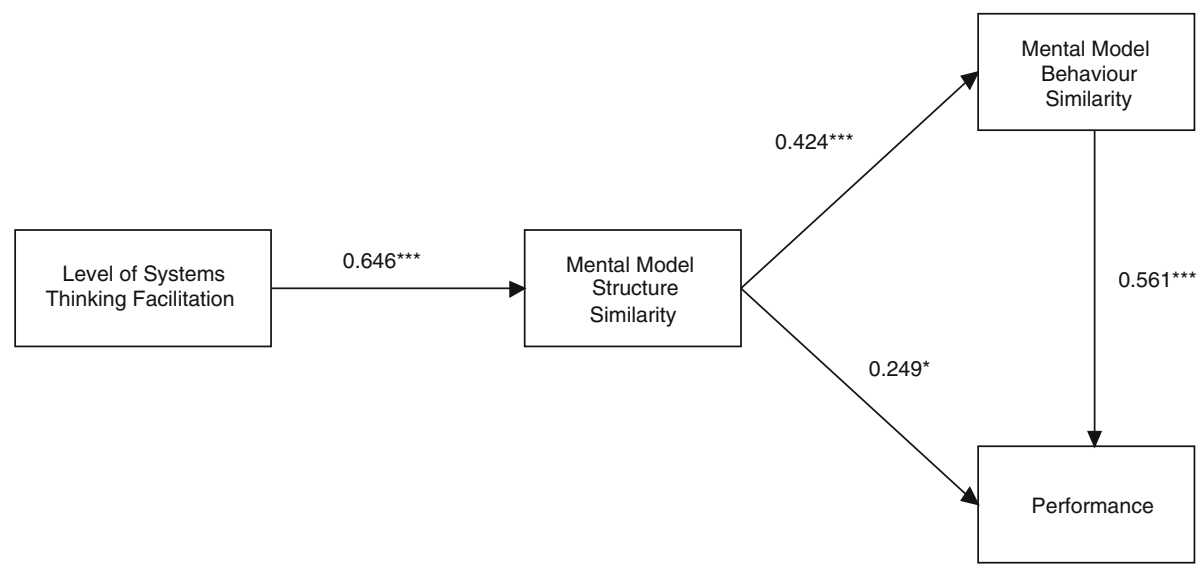

Fig. 6 Regression model with explanatory variables obtained through a stepwise regression (standardized Betas). * $P<0.05$; ** $P<0.005$; *** $P<0.001$

significant positive effect for Work Experience $(\beta=0.388, P=0.015)$, and no significant effects for other variables. Regression analysis on Performance shows a highly significant positive effect for Mental Model Behaviour Similarity $(\beta=0.540, P<0.001)$, a significant positive effect for Mental Model Structure Similarity $(\beta=0.401, P=0.002)$, a significant positive effect for Simulation Experience $(\beta=0.212, P=0.049)$, and no significant effects for other variables.

The regression model was refined by performing a stepwise regression in order to exclude the variables that did not seem to significantly explain the dependent variables and to preserve the most significant explanatory variables (Fig. 6). As presented in Fig. 6, regression analysis of Mental Model Structure Similarity on the most significant independent variables shows a very strong effect for Level of Systems Thinking Facilitation ( $\beta=0.646, P<0.001)$. Regression analysis of Mental Model Behaviour Similarity shows a highly significant effect for Mental Model Structure Similarity $(\beta=0.424, P<0.001)$. Regression analysis of Performance shows a highly significant effect for Mental Model Behaviour Similarity $(\beta=0.561, P<0.001)$ and a significant effect for Mental Model Structure Similarity $(\beta=249, P=0.014)$.

Unexpectedly, the results indicate that the variables Time (total time participants spent on the task) and Simulation Experience (previous experience in business game simulators) did not influence Mental Model Structure Similarity, Mental Model Behaviour Similarity or Performance. These results suggest that participants spent the amount of time they just needed to perform the task and as they familiarized themselves with the simulator by conducting the practice simulation, there was no additional benefit from previous experience in business simulators.

Testing of hypotheses

Figure 7 shows the regression model including the variables defined in the research model, showing a very strong effect for Level of Systems Thinking Facilitation $(\beta=0.529$, $P<0.001)$, low significance for Level of Feedback Information $(\beta=0.191, P=0.075)$, 


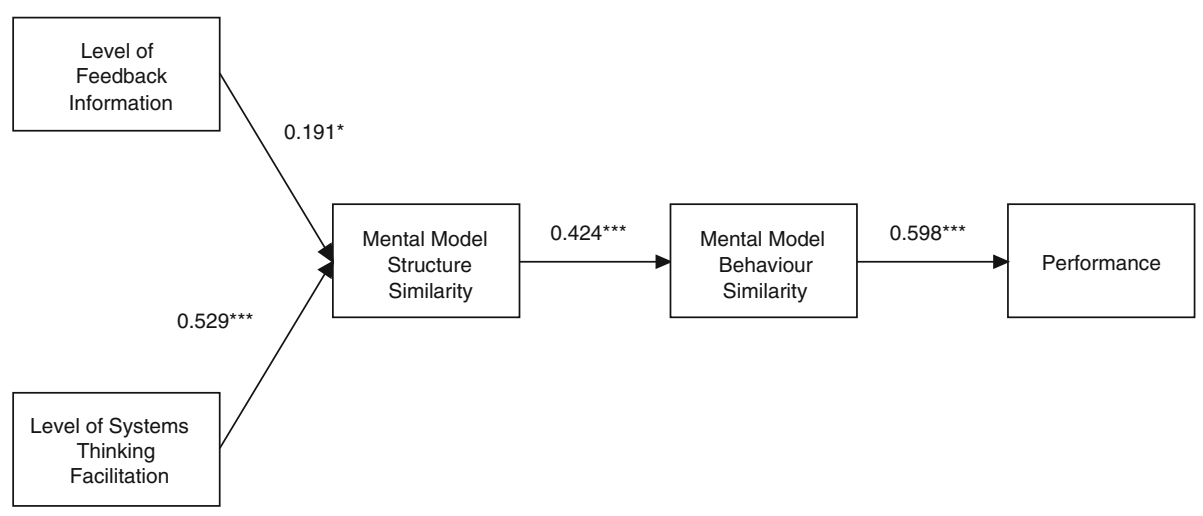

Fig. 7 Regressions used to assess the research model (standardized Betas). * $P<0.1$; *** $P<0.001$

Table 4 Summary of hypothesis testing

\begin{tabular}{lll}
\hline Hypotheses & Description & Results \\
\hline H1 & $\begin{array}{l}\text { The level of feedback information positively influences } \\
\text { mental model structure similarity } \\
\text { The level of systems thinking facilitation positively } \\
\text { influences mental model structure similarity } \\
\text { Mental model structure similarity positively mental } \\
\text { model behaviour similarity }\end{array}$ & $\begin{array}{c}\text { No significant relation } \\
\text { supported } \\
\text { Supported }\end{array}$ \\
H3 & $\begin{array}{l}\text { Mental model behaviour similarity positively influences } \\
\text { performance }\end{array}$ & Supported \\
H4 & Supported \\
\hline
\end{tabular}

a highly significant impact of Mental Model Structure Similarity on Mental Model Behaviour Similarity $(\beta=0.424, P<0.001)$ and a highly significant effect of Mental Model Behaviour Similarity on Performance $(\beta=0.598, P<0.001)$. These results confirm three of the four hypotheses (Table 4): H2 - The Level of Systems Thinking Facilitation positively influences Mental Model Structure Similarity, H3-Mental Model Structure Similarity positively influences Mental Model Behaviour Similarity, and H4-Mental Model Behaviour Similarity influences Performance.

On average, the participants from group B-high LFI and low LSTF—-showed a better Mental Model Structure Similarity than subjects from group A-low LFI and low LSTF. These results are shown in Table 1, with a significant difference evident in Table 2. However, the regression showed no significant effect of Level of Feedback Information on Mental Model Structure Similarity. Consequently, our research does not provide full support of Hypothesis H1-that the Level of Feedback Information positively influences Mental Model Structure Similarity. The balanced scorecard interface provides a more quality of feedback information than the financial scorecard interface because the performance indicators of the balanced scorecard capture the most relevant information about the system's behaviour. Nevertheless, these results suggest that by using such high quality level of feedback information solely, managers do not learn about the business system any more effectively than they would otherwise.

As we hypothesized, the results suggest that the process of causal diagramming gave participants from group $\mathrm{C}$ a powerful systems thinking tool that accelerated their learning 
about the simulated business system. Using the causal diagram for strategy review and implementation significantly improved the mental model structure similarity of participants, supporting Hypothesis H2-The Level of Systems Thinking Facilitation positively influences Mental Model Structure Similarity.

The results showed that improved mental model structure led to better mental model behaviour, supporting Hypothesis H3. We also found strong evidence of the fact that that improved mental model behaviour similarity led to better performance, on support of Hypothesis H4. Therefore, enhanced double-loop learning effectiveness (viewed as an improvement in mental models structure and simulation) seems to improve management performance.

\section{Conclusion}

This study is based on a laboratory experiment aimed at testing hypotheses about the role of the mental models in the strategic decision making process. The results of this simulation-based research provide useful contributions by reinforcing the importance of the Mental Model construct as a means of investigating how managers learn about their business context, infer future behaviour and its impact on organization performance. This study also emphasizes the effectiveness of system thinking facilitation, namely causal diagramming modelling techniques, as a basic strategy to improve mental models and decision making.

The dynamic decision-making theory based on mental models asserts that managers make decisions which are the result of applying rules and policies governed by their mental models. An erroneous mental model means that there are significant differences between the managers' perception and the reality. Several research questions regarding cognitive processes by which mental models are improved, and regarding the nature of how they determine intended actions and decisions, are the focus of other studies. One research question explores whether or not improved mental models of systems lead to better decisions. As suggested in similar previous research using the same simulator (RitchieDunham 2002), improved mental model structure similarity does lead to better performance.

Another general research question asks which learning processes and strategies can best improve mental models. A significant number of promising techniques based on systems thinking and modelling have emerged in order to improve mental models and dynamic decision making. This paper also documents some effects of interaction with systems modelling on mental models. The results suggest that to improve mental models, managers should take advantage of systems thinking tools like causal diagrams to model and review their understanding of the system. The participants' mental model of the simulated business context is only marginally improved when causal diagramming is not applied. This is due to the fact that participants receive critical information but act as a passive knowledge recipient as they accommodate that information in the existing mental structures. By using causal diagramming, participants strongly improve the capacity of learning as they become system modellers. They develop a systemic and dynamic overview of the business context, by framing a causal model representative of the critical cause-and-effect relations. This very simple tool of systems thinking, offers managers opportunities to modelling and learning about the context. Thus, this study suggests that to improve mental models managers should deal with very simple systems thinking approaches like causal diagrams to model and review their understanding of the system. 
Very little empirical research exists about the impact of using modelling tools on management performance. Other qualitative or/and quantitative methods of systems modelling have been proposing to improve management learning. Soft systems methodology and systems dynamics modelling and simulation are examples of those tools (Pidd 2004). Research is needed to explore, validate and contrast the effectiveness of those methods for supporting management learning.

Acknowledgments An earlier version of this paper was presented at the CELDA 2008 meeting in Freiburg, Germany and published in the CELDA 2008 Proceedings: Capelo, C., \& Dias, J. (2008). Exploring the role of mental models in strategic decision making. In Kinshuk, D. G. Sampson, J. M. Spector, P. Isaías, \& D. Ifenthaler (Eds.), Proceedings of the IADIS international conference on cognition and exploratory learning in the digital age (pp 10-17). IADIS: Freiburg, Germany. We want to thank the editor for excellent guidance and reviewers for valuable feedback.

\section{References}

Argyris, C. (1976). Increasing leadership effectiveness. New York: Wiley.

Checkland, P., \& Scholes, J. (1990). Soft systems methodology in action. Chichester: Wiley.

Copeland, T., Koller, T., \& Murrin, J. (2000). Valuation-measuring and management the value of companies. Chichester: Wiley.

Craik, K. (1943). The nature of explanation. Cambridge: Cambridge University Press.

Davis, F., \& Yi, M. (2004). Improving computer skill training: Behavior modeling, symbolic mental rehearsal, and the role of knowledge structures. The Journal of Applied Psychology, 89, 509-523. doi: 10.1037/0021-9010.89.3.509.

Eden, C., \& Ackermann, F. (1998). Strategy making: The journey of strategic management. London: Sage. Forrester, J. (1961). Industrial dynamics. Waltham, MA: Pegasus Communications.

Gary, M., \& Wood, R. (2007). Testing the effects of a system dynamics decision aid on mental model accuracy and performance on dynamic decision making tasks. In Proceedings of the 25th international conference of the system dynamics society, Boston, USA.

Gentner, D., \& Stevens, A. (Eds.). (1983). Mental models. Hillsdale, NJ: Lawrence Erlbaum Associates.

Howie, E., Sy, S., Ford, L., \& Vicente, K. (2000). Human-computer interface design can reduce misperceptions of feedback. System Dynamics Review, 16, 151-171. doi:10.1002/1099-1727(200023)16:3< 151::AID-SDR191>3.0.CO;2-0.

Huff, A., \& Jenkins, M. (Eds.). (2002). Mapping strategic knowledge. London: Sage.

Johnson-Laird, P. (1983). Mental models: Towards a cognitive science of language, in-ference and consciousness. Cambridge, MA: Harvard University Press.

Kaplan, R., \& Norton, D. (2001). The Strategy-focused organization: How balanced scorecard companies thrive in the new business environment. Boston, MA: Harvard Business School Press.

Mathieu, J., Goodwin, G., Heffner, T., Salas, E., \& Cannon-Bowers, J. (2000). The influence of shared mental models on team process and performance. The Journal of Applied Psychology, 85, 273-283. doi:10.1037/0021-9010.85.2.273.

Mathieu, J., Goodwin, G., Heffner, T., Salas, E., \& Cannon-Bowers, J. (2005). Scaling the quality of teammates' mental models: Equifinality and normative comparisons. Journal of Organizational Behavior, 26, 37-56. doi:10.1002/job.296.

Morecroft, J., Sanchez, R., \& Heene, A. (Eds.). (2002). Systems perspectives on resources, capabilities, and management process. Oxford: Pergamon.

Narciss, S. (2008). Feedback strategies for interactive learning tasks. In J. M. Spector, M. D. Merril, J. van Merrienboer, \& M. P. Driscoll (Eds.), Handbook of research on educational communications and technology (pp. 125-143). New York: Lawrence Erlbaum Associates.

Paich, M., \& Sterman, J. (1993). Boom, bust, and failures to learn in experimental markets. Management Science, 39, 1439-1458. doi:10.1287/mnsc.39.12.1439.

Pidd, M. (Ed.). (2004). Systems modelling-theory and practice. Chichester: Wiley.

Richardson, G., Andersen, D., Maxwell, T., \& Stewart, T. (1994). Foundations of mental model research. Stirling, Scotland: International System Dynamics Conference.

Ritchie-Dunham, J. (2002). Balanced scorecards, mental models, and organizational performance: A simulation experiment. University of Texas at Austin, USA: Doctoral Dissertation. 
Rowe, A., \& Cooke, N. (1995). Measuring mental models: Choosing the right tools for the job. Human Resource Development Quarterly, 6, 243-255. doi:10.1002/hrdq.3920060303.

Schvaneveldt, R. (1990). Pathfinder associative networks: Studies in knowledge organization. Norwood, NJ: Ablex.

Senge, P. (1990). The fifth discipline. New York: Doubleday.

Sengupta, K., \& Abdel-Hamid, T. (1993). Alternative conceptions of feedback in dynamic decision environments: An experimental investigation. Management Science, 39, 411-428. doi:10.1287/mnsc. 39.4.411.

Sterman, J. (1989). Modeling managerial behavior: Misperceptions of feedback in a dynamic decision making experiment. Management Science, 35, 321-339. doi:10.1287/mnsc.35.3.321.

Sterman, J. (2000). Business dynamics: System thinking and modeling for a complex world. New York: Irwin McGraw-Hill.

Stout, R., Salas, E., \& Kraiger, K. (1996). The role of trainee knowledge structures in aviation team environments. The International Journal of Aviation Psychology, 7, 235-350. doi:10.1207/s15327 108ijap0703_4.

Wyman, B., \& Randel, J. (1998). The relation of knowledge organization to performance of a complex cognitive task. Applied Cognitive Psychology, 12, 251-264. doi:10.1002/(SICI)1099-0720(199806) $12: 3<251::$ AID-ACP510>3.0.CO;2-F.

Carlos Capelo holds a PhD from ISCTE in Strategic Management. He is Professor of Management at Universidade Lusófona and Instituto Superior de Gestão, Lisbon, Portugal. He has also been developing a management career in Galp Energia, a Portuguese oil \& gas company. His main research areas are related to strategic learning and business modelling and simulation.

João Ferreira Dias holds a PhD from ISCTE in Management. He is Invited Professor of Management at EBAP-Fundação Getúlio Vargas (Brasil) and IUCAI (S.Tomé). His main research areas are related to strategic management and system dynamics. 